\title{
Analysis of expressed sequence tags derived from the endophytic fungus Neotyphodium Iolii grown in vitro and in association with its host plant perennial ryegrass
}

\author{
R. JOHNSON ${ }^{1}$, A. KHAN ${ }^{2}$, C. VOISEY ${ }^{1}$, S. BASSETT ${ }^{1}$, C. GABORIT ${ }^{1}$, L. JOHNSON ${ }^{1}$, M. CHRISTENSEN ${ }^{1}$, A. $^{2}$ \\ MCCULLOCH ${ }^{3}$ and G. BRYAN ${ }^{1}$. \\ ${ }^{1}$ Forage Biotechnology, AgResearch, Private Bag 11008, Palmerston North, New Zealand. \\ ${ }^{2}$ Bioinformatics, Mathematics and Statistics, AgResearch, Private Bag 50034, Mosgiel, New Zealand \\ ${ }^{3}$ Information Services, AgResearch, Private Bag 50034, Mosgiel, New Zealand \\ richard.johnson@agresearch.co.nz
}

\begin{abstract}
As a first step towards a functional genomics approach to gain a greater understanding of this important symbiosis, we have generated, sequenced and analysed two EST libraries from cultures of $N$. lolii and six in planta subtracted EST libraries enriched for differentially expressed genes. A total of 12871 ESTs were sequenced which, after filtering for quality, clustered into 1066 contigs and 3230 singletons to give a set of 4296 unique sequences or unigenes. BLASTX analysis revealed that $60 \%$ of fungal sequences derived from cultures were of unknown function with a sub-set of these corresponding to orphans. For the in planta-derived ESTs, most of the sequences with homologs in the public databases (98\%) were of ryegrass origin. Comparisons made against fully sequenced genomes revealed that most fungal ESTs were homologous to genes present in both pathogenic and non-pathogenic ascomycete filamentous fungi, whereas the subtracted libraries comprised mostly plant genes. A range of sequences having significant homology to demonstrated pathogenicity/virulence genes in other fungal pathosystems were also identified, as well as some ESTs with proven roles in endophyte secondary metabolism.
\end{abstract}

Keywords: ESTs, cDNA, Neotyphodium lolii, Lolium perenne, symbiosis, mutualism, suppression subtractive hybridisation

\section{Introduction}

Forage grasses belonging to the sub-family pooideae, including several important forage and turf species, often harbour endophytic fungi belonging to the genus Neotyphodium and Epichloë (Clavicipitaceae, Ascomycota). These endophytes live entirely within the intercellular spaces of their grass hosts and infection is symptomless, with the endophyte relying entirely on the host plant for dissemination via the seed or through vegetative structures (reviewed by Schardl et al. 2004).

The association is mutually beneficial since the endophyte confers a number of biotic and abiotic advantages to the host, including enhanced plant growth, protection from certain mammalian and insect herbivores, enhanced resistance to nematodes, resistance to some fungal pathogens and in some associations, enhanced drought tolerance (Johnson et al. 2003). Some of these benefits are due to the production of fungal secondary metabolites such as peramine, loline, ergopeptine and indole diterpene alkaloids (Tanaka et al. 2005; Spiering et al. 2005; Panaccione et al. 2001; Young et al. 2006), some of which also cause associated mammalian toxicosis. Evidence has also accumulated showing that the host plant has a significant effect on the regulation of fungal secondary metabolites (Lane et al. 2000) and more recently it has been shown that the expression of fungal genes involved in alkaloid production are up-regulated in planta (Tanaka et al. 2005; Young et al. 2005).
Apart from the characterised role of the above mentioned fungal secondary metabolites during symbiosis, many of the other observed endophyte effects on their host plants have not been elucidated. Whilst genomic resources for fungal researchers have significantly advanced over the past few years, particularly in respect to ESTs, these have generally focused on pathogenic, model saprophytic or important industrial fungi. In this paper we describe a functional genomics approach to dissect the molecular mechanisms underlying the symbiosis between endophytic fungi and their grass hosts, in which we generated, sequenced and analysed two EST libraries from cultures of $N$. lolii and six in planta subtracted EST libraries enriched for differentially expressed genes.

\section{Materials and Methods}

\section{Endophyte strains and plant infection}

An asexual wild type $N$. lolii strain, Lp19 (Christensen et al. 1993) isolated from Nui perennial ryegrass was chosen for this study because it synthesises three of the four important known symbiosis-associated secondary metabolites (peramine, ergovaline and lolitrem), has a relatively small genome size $(\sim 35$ $\mathrm{Mb}$ ), is stable in culture and is typical of endophytes isolated from perennial ryegrass pastures. Isogenic ryegrass plants infected (G1056) or uninfected (G1057) with N. lolii strain Lp19 were obtained as previously described (Tanaka et al. 2005). Plants of G1056 and G1057 plants were grown under identical conditions under glass until harvest.

\section{Growth of endophyte strains in vitro}

To generate ESTs from endophytes grown in a complete medium, $N$. lolii strain Lp19 was grown in $50 \mathrm{ml}$ potato dextrose broth and incubated for 10 days at $22^{\circ} \mathrm{C}$. Mycelia for RNA extraction were harvested under vacuum using a sterile Buchner funnel containing two layers of Whatman 3 MM paper. To generate ESTs from endophyte grown in a minimal medium, mycelia from cultures initially grown in complete medium for 14 days were harvested as described above. Two grams of mycelia was used to inoculate $50 \mathrm{ml}$ of Blankenship medium (Blankenship et al. 2001) and the cultures incubated for a further 19 days at $22^{\circ} \mathrm{C}$. Mycelia for RNA extraction were harvested as for complete medium.

\section{Preparation of in vitro grown cDNA libraries}

Polyadenylated mRNA was purified from total RNA using standard procedures. cDNA libraries were created using the SMART cDNA Library Construction Kit (Clontech) and $\lambda$ TriplEx $2^{\mathrm{TM}}$ vector (Clontech) according to the manufacturers instructions. Two libraries were contructed, one from minimal media (NL19MM) and one from defined media (NL19EPD). ESTs were sequenced using Big Dye 3.1 (ABI) cycle sequencing reagents on an $\mathrm{ABI} 3100$ automated sequencer. 
Table 1 Numbers of unisequences that have homology to known or unknown proteins, and those that are orphans. The unknowns category includes those unisequences with hits to hypothetical/predicted proteins, and those with no hits (orphans).

\begin{tabular}{cccc}
\hline $\begin{array}{c}\text { Contig } \\
\text { build }\end{array}$ & $\begin{array}{c}\text { Homology } \\
\text { to known } \\
\text { proteins }\end{array}$ & $\begin{array}{c}\text { Homology } \\
\text { to unknown } \\
\text { proteins }\end{array}$ & Orphans \\
\hline CS32 & $695(34.6 \%)$ & $1,316(65.4 \%)$ & $1,224(60.9 \%)$ \\
CS36 & $1,520(66.5 \%)$ & $765(33.5 \%)$ & $318(13.9 \%)$ \\
\hline
\end{tabular}

Figure 1A Inter-library overlap in terms of EST composition: NL19EPD vs. NL19EMM in vitro libraries. Interlibrary overlap was determined on the basis of contig membership.

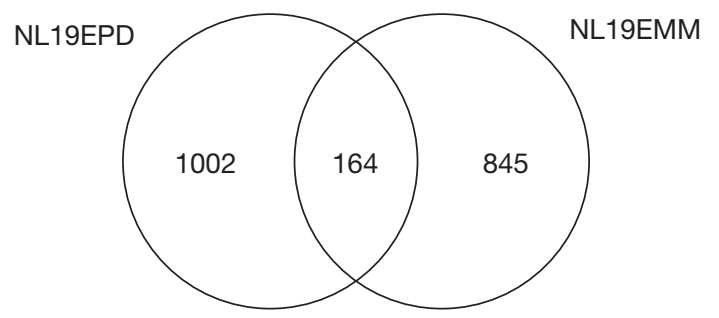

Figure 1B Inter-library overlap in terms of EST composition: Combined up-regulated $(+)$ vs. combined down-regulated (-) subtracted libraries.

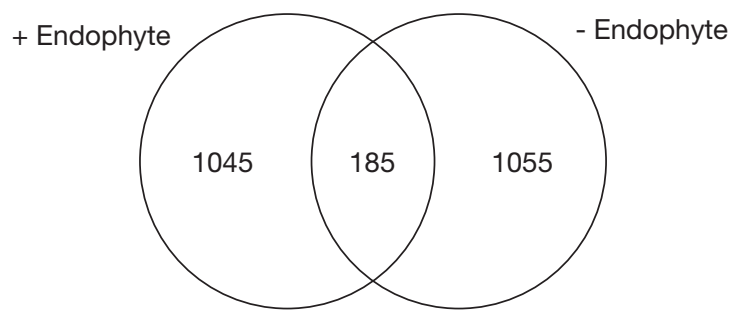

Preparation of subtracted cDNA libraries by suppression subtractive hybridization (SSH)

SSH (Diachenko et al. 1996) was performed as described previously (Young et al. 2006), except that mature, immature, and seedling tissue was harvested separately. Mature tissue (cv. Nui), comprising the outer leaf sheath and blade was dissected away from the emerging immature leaf tissue using a sterile scalpel blade. Both tissue dissections were immediately frozen in liquid nitrogen and stored until RNA extraction. For seedling material, seeds of cultivar Samson were surface sterilised and germinated on water agar plates. After 9 days, elongated hypocotyls were harvested above the seed, immediately frozen in liquid nitrogen and stored until RNA extraction. ESTs were sequenced using Big Dye $3.1(\mathrm{ABI})$ cycle sequencing reagents on an $\mathrm{ABI} 3100$ automated sequencer.

\section{Results}

\section{EST libraries}

We generated eight independent EST libraries. Two were from $N$. lolii grown in vitro (together designated CS32) and six were from suppression subtractive hybridisations between endophyte infected and endophyte free perennial ryegrass (together designated CS36). A total of 5493 and 3896 ESTs were sequenced for CS32 and CS36, respectively. For library CS32, ESTs assembled into 412 contigs and 1599 singletons to provide a set of 2011 unisequences with an average length of 716 base pairs. For library CS36, ESTs assembled into 654 contigs and 1631 singletons to provide a set of 2285 unisequences with an average length of 377 base pairs. Overlap of expression between the two in vitro fungal derived libraries that comprise CS32 was determined on the basis of contig membership (Fig. 1A). For the subtracted SSH libraries we compared the overlap between the combined up-regulated and down-regulated libraries (Fig. 1B). In both cases the majority of contigs or singletons showed no overlap indicating that most unisequences were library specific.

\section{EST comparison against fungal and plant databases}

We analysed the contigs in CS32 and CS36 to determine what proportion of unisequences had significant homology to proteins of known or unknown function, as well as determining the percentage of orphan sequences (Table 1). Contig builds were compared by BLASTX analysis against the NCBI non redundant (nr) protein database, using an e-value cut-off of 1e-5, and the top five hits for each contig were examined. Orphans were confirmed using additional TBLASTX searches against ESTs and ORFs from 25 fungal and 11 plant species.

\section{Functional classification of CS32 and CS36}

We have annotated each EST in CS32 and CS36 with one or multiple functional categories which define the function of the gene product. Functional categories were selected from the MIPS Functional Catalogue (FunCat) (Ruepp et al. 2004) and are represented as pie charts for CS32 and CS36, respectively (Figure 2A and 2B). BLASTX analysis revealed that $60 \%$ of EST sequences from cultures of $N$. lolii were of unknown function with a sub-set of these corresponding to orphans. Comparisons made against fully sequenced genomes revealed that most fungal ESTs were homologous to genes present in both pathogenic and non-pathogenic ascomycete filamentous fungi, whereas the subtracted libraries comprised mostly plant genes.

\section{Discussion}

This study has provided significant EST resources for $N$. lolii grown in vitro and this has been of critical importance in aiding our proteomics approach in which we have identified proteins differentially expressed during this symbiosis using the same infected and uninfected isogenic plant lines reported here (Johnson et al. 2007).

We have also investigated the molecular genetics of the symbiosis between Neotyphodium lolii and its host plant Lolium perenne. Unlike many fungal pathogens, where fungal biomass can accumulate to relatively high levels in relation to their hosts, endophytic fungi of the Neotyphodium/Epichloë complex primarily colonise the meristematic parts of their grass hosts and fungal biomass has been shown to be concomitantly low; less that $0.5 \%$ at the level of DNA (Panaccione et al. 2001; Johnson et al. 2003). This presents a technical challenge to identify $N$. lolii ESTs that are expressed in planta, which is why we used suppression subtractive hybridisation to enrich specifically for ESTs expressed during the symbiosis. Analysis of the SSH libraries identified several fungal genes that have a known role in the symbiosis, for example lolitrem biosynthesis (Young et al. 2006), $\beta$-1, 6-glucanase (Moy et al. 2002), a proteinase (Reddy et al. 1996), a chitinase (Li et al. 2004), as well as others with 
Figure 2 Functional classification of ESTs from in vitro and subtracted (SSH) libraries, based on homology to known proteins and protein domains from BLAST and InterProScan searches. ESTs were annotated with one or multiple FunCat categories; only those ESTs with annotations are included in the charts.

\section{Key}

$\square 01$ Metabolism
$\square 01.01$ Amino acid metabolism

$\square 01.05 \mathrm{C}$-compound and carbohydrate metabolism

$\square 01.06$ Lipid, fatty acid and isoprenoid metabolism

口 01.20 Secondary metabolism

$\square 02$ Energy

$\square 02.01$ Glycolysis and gluconeogenesis

$\square 02.07$ Pentose-phosphate pathway

口 02.10 Tricarboxylic-acid pathway

$\square 02.19$ Metabolism of energy reserves

$\square 02.30$ Photosynthesis

$\square 04$ Storage protein

$\square 10$ Cell cycle and DNA processing

$\square 11$ Transcription

$\square 12$ Protein synthesis

$\square 14$ Protein fate

$\square 16$ Protein with binding function or cofactor requirement

$\square 18$ Protein activity regulation

$\square 20$ Cellular transports

$\square 30$ Cellular communicationisignal transduction mechanism

$\square 32$ Cell rescue, defense and virulence

$\square 32.01$ Stress response

$\square 32.05$ Disease, virulence and defense

$\square 34$ Interaction with the cellular environment

$\square 36$ Interaction with the environment

$\square$ 36.20 Plantifungal specific systemic sensing and response

$\square 38$ Tranposable elements, viral and plasmid proteins

$\square 40$ Cell fate

$\square 41$ Development

$\square 42$ Biogenesis of cellular components

$\square 43$ Cell type differentiation

$\square 45$ Tissue differentiation

$\square 47$ Organ differentiation
Figure 2A In vitro EST libraries (CS32). 42\% of ESTs were annotated with one or more FunCat categories.

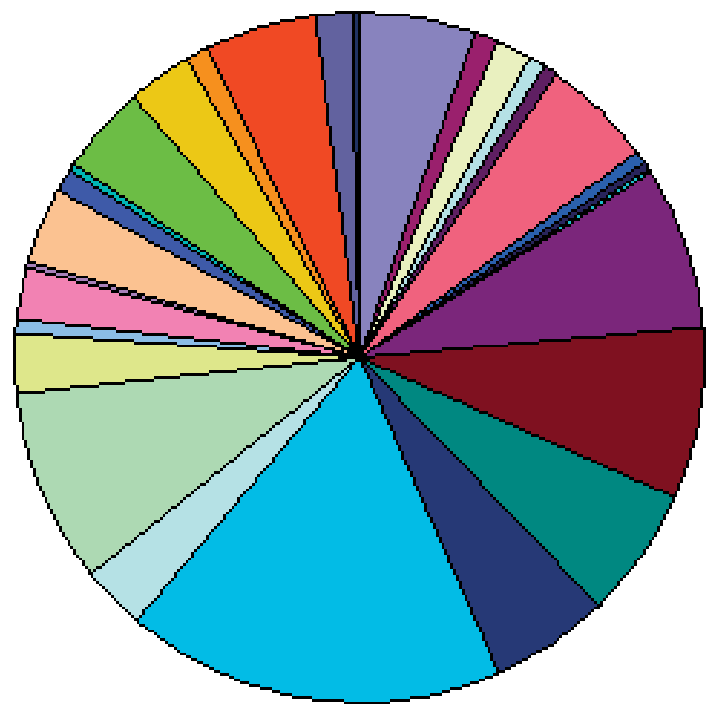

Figure 2B Subtracted (SSH) libraries (CS36). 64\% of ESTs were annotated with one or more FunCat categories.

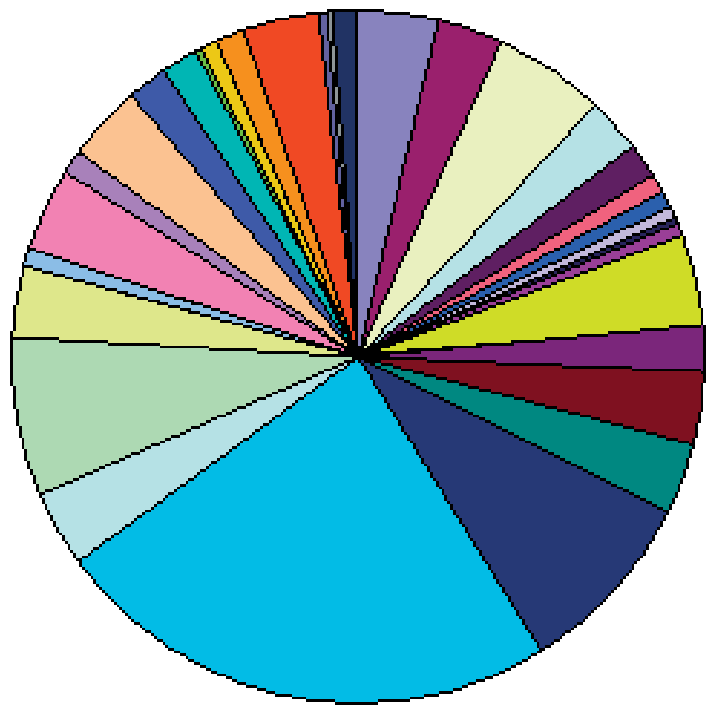

\section{ACKNOWLEDGEMENTS}

Funding has been provided by the Foundation of Research Science and Technology (C10X0203).

\section{REFERENCES}

Blankenship, J.D.; Spiering, M.J.; Wilkinson, H.H.; Fannin, F.F.; Bush, L.P.; Schardl, C.L. 2001. Production of loline alkaloids by the grass endophyte, Neotyphodium uncinatum, in defined media. Phytochemistry 58: 395-401.

Christensen, M.J.; Leuchtmann, A.; Rowan, D.D.; Tapper, B.A. 
1993. Taxonomy of Acremonium endophytes of tall fescue (Festuca arundinacea), meadow fescue (F. pratensis) and perennial ryegrass (Lolium perenne). Mycological Research 97:1038-1032.

Diachenko, L.; Lau, Y.F.; Campbell, A.P.; Chenchik, A.; Mogadam, F.; Huang, B.; Lukyanov, S.; Lukyanov, K.; Gurskaya, N.; Sverdlov, E.D.; Siebert, D. 1996. Suppression Subtractive Hybridization: A method for generating differentially regulated or tissue-specific cDNA probes and libraries. Proceedings of the. National Academy of Science USA 93: 6025-6030.

Johnson, L.J.; Johnson, R.D.; Schardl, C.L.; Panaccione, D.G. 2003. Identification of differentially expressed genes in the mutualistic association of tall fescue with Neotyphodium coenophialum. Physiological and Molecular Plant Pathology 63: 305-317.

Johnson, R.D.; Bassett, S.; Christensen, M.C.; Gaborit, C.N.; Johnson, L.J.; Khan, A.K.; Koulman, A.; Rasmussen, S.; Voisey, C.R.; Bryan, G.T. 2007. Functional genomics of the Neotyphodium lolii / ryegrass symbiosis Pp 443 In: Proceedings of the 6th International Symposium on Fungal Endophytes of Grasses. Grassland Research and Practice Series No. 13. New Zealand Grassland Association.

Lane, G.A.; Christensen, M.J.; Miles, C.O. 2000. Coevolution of fungal endophytes with grasses: the significance of secondary metabolites. pp. 342-388. In: Microbial Endophytes. Eds. Bacon, C.W.; White, J.F. Jr. Marcel Dekker, New York.

Li, H.M.; Sullivan, R.;Moy, M.; Kobayashi, D.Y.; Belanger, F.C. 2004.Expression of a novel chitinase by the fungal endophyte in Poa ampla. Mycologia 96: 526-536.

Moy, M.; Li, H.M.; Sullivan, R.; White, J.F.Jr.; Belanger, F.C. 2002. Endophytic fungal beta-1,6-glucanase expression in the infected host grass. Plant Physiology 130: 1298-1308.

Panaccione, D.G.; Johnson, R.D.; Wang, J.; Young, C.A.; Damrongkool, P.; Scott, B.; Schardl, C.L. 2001. Elimination of ergovaline from a grass-Neotyphodium endophyte symbiosis by genetic modification of the endophyte. Proceedings of the National Academy of Science U S A. 98: 12820-12825.

Reddy, P.V.; Lam, C.K.; Belanger, F.C. 1996. Mutualistic fungal endophytes express a proteinase that is homologous to proteases suspected to be important in fungal pathogenicity. Plant Physiology 111: 1209-1218.

Ruepp,A.; Zollner, A.; Maier, D.; Albermann, K.; Hani, J.; Mokrejs, M.; Tetko, I.; Guldener, U.; Mannhaupt, G.; Munsterkotter, M.; Mewes, H.W. 2004. The FunCat, a functional annotation scheme for systematic classification of proteins from whole genomes. Nucleic Acids Research 32(18): 5539-5545.

Schardl, C.L.; Leuchtmann, A.; Spiering, M.J. 2004. Symbioses of grasses with seedborne fungal endophytes. Annual Review of Plant Biology 55: 315-340.

Spiering, M.J.; Moon, C.D.; Wilkinson, H.H.; Schardl, C.L. 2005. Gene clusters for insecticidal loline alkaloids in the grass-endophytic fungus Neotyphodium uncinatum. Genetics 169: 1403-1414.

Tanaka, A.; Tapper, B.A.; Popay, A.; Parker, E.J.; Scott, B. 2005. A symbiosis expressed non-ribosomal peptide synthetase from a mutualistic fungal endophyte of perennial ryegrass confers protection to the symbiotum from insect herbivory. Molecular Microbiology 57: 1036-1050.

Voisey, C.R.; Khan, A.K.; Park-Ng, Z.A.; Johnson, L.J.; Johnson, R.D.; Cao, M.; Bassett, S.; Gaborit, C.N.; McCulloch, A.F.; Simon, D.; Ramakrishna, M.; Rasmussen, S.; Bryan, G.T. 2007. Development of an Affymetrix dual genome (Neotyphodium lolii/ Lolium perenne) Symbiosis GeneChip ${ }^{\circledR}$. pp. 505 ' $n$ : Proceedings of the 6th International Symposium on Fungal Endophytes of Grasses. Grassland Research and Practice Series No. 13. New Zealand Grassland Association.

Young, C.A.; Bryant, M.K.; Christensen, M.J.; Tapper, B.A.; Bryan, G.T.; Scott, B. 2005. Molecular cloning and genetic analysis of a symbiosis-expressed gene cluster for lolitrem biosynthesis from a mutualistic endophyte of perennial ryegrass. Molecular Genetics and Genomics 274: 13-29.

Young, C.A.; Felitti, S.; Shields, K.; Spangenberg, G.; Johnson, R.D.; Bryan, G.T.; Saikia, S.; Scott, B. 2006. A complex gene cluster for indole-diterpene biosynthesis in the grass endophyte Neotyphodium lolii. Fungal Genetics and Biology 43: 679-693. 